\title{
Lung Transplantation for Acute Respiratory Distress Syndrome
}

\author{
Ankit Bharat, $\mathrm{MD}^{\mathrm{a}, *}$, Konrad Hoetzenecker, $\mathrm{MD}^{\mathrm{b}}$
}

\section{KEYWORDS}

- Acute respiratory distress syndrome $\bullet$ Lung transplantation • Acute lung injury • Lung failure

\section{KEY POINTS}

- Despite optimized medical treatment, the mortality in patients with severe acute respiratory distress syndrome (ARDS) remains high

- Lung transplant is a life-saving treatment in carefully selected patients with ARDS

- Despite the complex medical course before transplantation, posttransplant survival in patients with ARDS is excellent

\section{INTRODUCTION}

The World Health Organization reports that respiratory illnesses are one of the top 5 causes of global deaths). For example, influenza alone causes 40 to 60 million new infections each year in the United States alone with 40 to 60,000 deaths; a large majority due to the development of lung injury and the acute respiratory distress syndrome (ARDS). Both infectious and noninfectious etiologies cause ARDS. While the global population-based estimate of the incidence of ARDS is mere approximations, it can vary from about 3.65 to 86.0 cases per 100,000 personyears. ${ }^{1,2}$ The incidence in the United States is one of the highest, ranging from 64.2 to 86.0 cases $/ 100,000$ person-years or about 200,000 cases annually. ${ }^{3}$ It is estimated that about $10 \%$ to $15 \%$ of patients admitted to the intensive care unit (ICU) and up to $23 \%$ of mechanically ventilated patients meet the definition of ARDS. ${ }^{4-7}$ In an international study of nearly 30,000 ICU patients, $10 \%$ of admissions to the ICU were due to ARDS. ${ }^{8}$ Accordingly to the Berlin definition, ARDS is classified as mild, moderate, or severe, based on the ratio of arterial partial pressure of oxygen $\left(\mathrm{Pa}_{\circ 2}\right)$ and fraction of inspired oxygen $\left(\mathrm{FiO}_{2}\right)$ of
300,200 , and $100 \mathrm{~mm} .{ }^{9}$ Only about $25 \%$ of ARDS cases are initially classified as mild while $75 \%$ are moderate to severe. A third of the mild cases go on to progress to moderate or severe disease. The mortality associated with mild, moderate, and severe disease is $27 \%, 32 \%$, and $45 \%$, respectively, with a pooled mortality of about $43 \% .^{10,11}$ Hence, the burden of disease from ARDS is tremendous.

\section{Pathophysiology of Acute Respiratory Distress Syndrome Resulting in End-stage Lung Disease}

ARDS represents a common terminal pathway of lung injury that spans highly variable phases in response to a variety of etiologies. It starts with alveolar-capillary damage leading to a proliferative phase, usually associated with lung healing and improvement in pulmonary function, and ultimately resulting in a fibrotic phase, which marks the end of the acute injury. The key histologic changes include alveolar edema, endothelial and epithelial injury, and leakage of proteinaceous fluid and blood into the alveolar space. Patients with ARDS are susceptible to nosocomial infections, multiorgan dysfunction, and baro- or volutrauma, which along with their underlying health

\footnotetext{
a Division of Thoracic Surgery, Northwestern University Feinberg School of Medicine, Chicago, USA;

b Department of Thoracic Surgery, Medical University of Vienna, Vienna, Austria

* Corresponding author.

E-mail address: abharat@nm.org
}

Twitter: @AnkitbharatMD (A.B.); @khoetzenecker (K.H.) 
status and comorbidities can influence the outcomes, which range from spontaneous recovery to severe lung parenchymal necrosis, bronchiectasis, or fibroproliferation. With advances in ICU care, the mortality in patients with severe ARDS has decreased but still remains substantial. ${ }^{12}$ Death early in the course of severe ARDS is related to complications such as pneumonia, sepsis, and multiorgan dysfunction. However, in those who survive the early infectious complications, the development of fibroproliferation can predispose to nosocomial complications with the inability to wean the mechanical life support, ultimately leading to the redirection of care to comfort measures in a large proportion of patients. ${ }^{13}$

Studies indicate that substantial fibroproliferation resulting in insufficient pulmonary function is common in patients with ARDS. ${ }^{14-16}$ Evidence of extensive collagen deposition has been described as early as the first 72 hours following the onset of ARDS $^{17,18}$ and presence of collagen products, such as procollagen peptide III, correlate with fatal outcomes. ${ }^{19}$ The release of profibrotic chemicals such as TGF- $\beta_{1}$ and insulin-like growth factor-I have been shown to be released and proposed to contribute to the fibroproliferative response in patients with ARDS. ${ }^{20}$ Clinically evident fibroproliferation is common even with the low tidal volume ventilation. ${ }^{21}$ Pulmonary fibrosis is characterized by aberrant and disorganized collagen deposition in the lung parenchyma, particularly affecting the alveolar spaces, similar to that observed in some chronic end-stage lung diseases.

We recently compared the three-dimensional matrix organization of normal human lungs with those obtained from either patients with severe COVID-19 ARDS or those with end-stage idiopathic pulmonary fibrosis necessitating transplantation. While normal human lungs showed a well-formed intricate matrix, those obtained from COVID-19 ARDS showed a complete absence of matrix organization with punctate islands of cells surrounding fibrotic airway regions. This pattern was similar to that observed in lungs from patients with end-stage idiopathic pulmonary fibrosis. ${ }^{22,23}$ Transcriptional atlases created using single-cell RNAsequencing (RNA-Seq) ${ }^{24-27}$ have identified unique cell populations in the fibrotic lung that could be causally implicated in the development of fibrosis. ${ }^{28-31}$ Using a transfer learning approach ${ }^{32}$ to compare single-cell RNA-Seq data from lung tissue of patients with end-stage pulmonary fibrosis ${ }^{26}$ and COVID-19 ARDS, we found striking homology between the 2 across many cell populations. We additionally found that a population of cells, expressing TP63, KRT5, KRT17, LAMB3, LAMC2, VIM, CHD2, FN1, COL1A1, TNC, HMGA2, and several senescence markers (CDKN1A, CDKN2A, CCND1, CCND2, MDM2, SERPINE1), accumulate during fibrosis, potentially contributing to disease pathogenesis through the expression of TGFB1, ITGAV and ITGB6. ${ }^{26,27}$ In the normal lung, expression of $K R T 17$ is restricted to basal, club, and ciliated cells in the proximal airways but they are absent in distal airways. ${ }^{24,26}$ In contrast to the normal lungs, these cells were readily observed in patients with end-stage COVID-19 and pulmonary fibrosis in distal airways. Furthermore, direct comparison of differential gene expression in KRT17+ cells between patients with pulmonary fibrosis and COVID-19 did not identify genes uniquely present in one condition, further highlighting similarities between these conditions. Additionally, comparison of differential gene expression in macrophages between patients with pulmonary fibrosis and COVID-19 ARDS also demonstrated considerable similarities between these 2 conditions. Our analysis also identified a small group of cells observed in patients with COVID-19 ARDS characterized by either expression of genes involved in calcium (AK5, SIGLEC15, CKB, and SLC9B2), iron (SLC40A1, CD163), and lipid (MERTK, PLTP, $A B C A 1)$ metabolism, as well as motility and immune signaling (MARCKS, TLR2, CCL20), likely reflecting superinfection and ongoing inflammation in patients with ARDS. ${ }^{22,23}$ Profibrotic macrophages stimulate fibroblasts by forming selfsustaining circuits promoted by the autogenous release of growth factors. ${ }^{33,34}$ Our data indicated that fibroblasts from patients with pulmonary fibrosis and those from patients with severe COVID-19 were largely similar. Collectively, these data suggest that some patients with COVID-19 ARDS develop end-stage lung disease, which is similar to other conditions such as pulmonary fibrosis.

Unfortunately, no medical or pharmacologic therapies targeting fibroproliferation have been effective. Steroids have also failed to show improvement in outcomes in patients with ARDSassociated fibroproliferation. ${ }^{35}$ Other agents such as tyrosine kinase inhibitors. ${ }^{36}$ compounds that target extracellular matrix proteins, ${ }^{37}$ and TGF- $\beta$ directed therapies ${ }^{38}$ are in the exploratory phase and their role in preventing fibroproliferation remains unknown. As such, lung transplantation is the only possible solution for selected patients with ARDS who develop end-stage pulmonary fibrosis.

\section{Clinical Considerations for Lung Transplantation}

The medical debate about the use of lung transplantation for patients with ARDS is centered 
around the topics of "benefit" and "candidacy." Concerns include the potential for recurrence of the inciting infections in the allograft, technical challenges imposed by the acute injury to the native lung, and potential risk for allograft infection by pathogens associated with ventilatorassociated pneumonia in the native lung. More importantly, the native lung might recover, resulting in long-term outcomes preferable to transplant. We believe that the following 2 broad criteria could be considered to determine the need for transplantation in patients with ARDS. First, the lung damage is sufficient to prevent weaning from the mechanical life support, both the mechanical ventilator and/or extracorporeal membrane oxygenation (ECMO) support, after sufficient time from the onset of ARDS has elapsed and optimized medical treatment has been administered. Second, there is a development of pulmonary or pleural complications which are refractory to medical treatment. Some common scenarios associated with these criteria include the development of fibroproliferative ARDS, lung necrosis with cavitation or pneumatoceles, or severe bronchiectasis. How to accurately identify patients who would not recover spontaneously and benefit from lung transplantation remains unclear. The preferred approach in our experience has been to continue to provide medical management in patients as long as lung recovery is deemed possible as patients have been reported to spontaneously recover after an extended duration of extracorporeal life support (ECLS). ${ }^{22,23}$ Lung transplant should be considered when sufficient time has elapsed as the onset of ARDS and lung recovery is deemed unlikely. Consideration of lung transplantation too early in the course could result in the deviation of the care pathway away from spontaneous recovery, reducing its likelihood. While the duration of time necessary to determine irreversibility is unclear at this time, we suggest that at least 4 to 6 weeks be allowed following the onset of ARDS before considering lung transplantation. However, exception could be made when severe pulmonary complications such as pulmonary hypertension with concomitant right ventricular failure, refractory nosocomial pneumonia, or recurrent pneumothoraces, develop that cannot be medically managed with or without ECMO. For COVID-19-associated ARDS, following the stipulated time, we have found the following indicators to be helpful in the medical decisionmaking for lung transplant consideration: (1) development of pulmonary sequelae as described above, (2) presence of lung necrosis with cavitation especially if associated with sepsis, (3) presence of significant pulmonary hypertension, (4) lung compliance less than $20 \mathrm{~mL} / \mathrm{cm} \mathrm{H} 2 \mathrm{O}$, and (5) evidence of diffuse pulmonary fibrosis. Transplantation should be deferred in patients who show signs of lung recovery, as suggested by improvement in lung compliance, chest radiographs, and gas exchange. We have previously proposed an approach to transplant consideration for patients with severe COVID-19-associated ARDS. ${ }^{22,39}$ Given the similarities between COVID-19 and non-COVID-19 ARDS, we believe that the same principles can be used for all patients with ARDS.

\section{Review of Available Literature and Reported Outcome of Lung Transplantation for Acute Respiratory Distress Syndrome}

While posttransplant outcomes for chronic lung diseases are established, the benefit of lung transplantation for ARDS is still emerging. ${ }^{40}$ Patients with severe ARDS are critically ill and develop considerable ICU-related comorbidities by the time lung recovery is deemed unlikely and transplant is considered. The medical course of severe ARDS is also often complicated by pulmonary complications such as pneumothorax, hemothorax, empyema, lung necrosis, and nosocomial pneumonia. ${ }^{41}$ Hence, there are concerns related to the technical feasibility of lung transplantation in these patients, potentially inferior posttransplant outcomes due to frailty, and recurrence of nosocomial pathogens following transplantation. Besides a handful of case reports, 3 larger case series on lung transplantation for ARDS have been published to date (Table 1). The first series reported the experience of this practice in a cohort of Korean patients. A total of 14 patients were evaluated and 9 ultimately received a transplantation between 2008 and 2013. ${ }^{40}$ Importantly, 3 of the transplants were in fact combined heart-lung transplantation due to left ventricular failure, right-sided heart insufficiency, or severe pulmonary hypertension. In 2021, Harano and colleagues performed a retrospective UNOS registry analysis. This represents the largest case series to date, including 65 patients listed for lung transplantation between 2005 and $2018 .{ }^{42}$ Sixty-one percent $(n=39)$ reached transplantation. The remaining patients were delisted either due to further deterioration or because their native lungs ultimately recovered. Recently, Frick and colleagues presented a combined report from 3 European high-volume lung transplant centers (Vienna-Austria; Leuven- Belgium; GroningenNetherlands). ${ }^{43}$ Between 1998 and 2018, 13 patients were transplanted for ARDS. While all published patient series included patients with 
Table 1

Studies reporting lung transplantation for ARDS

\begin{tabular}{|c|c|c|c|}
\hline Authors & $\begin{array}{l}\text { Chang et al. (Korean } \\
\text { Single-Center) }\end{array}$ & $\begin{array}{l}\text { Harano et al. } \\
\text { (UNOS Database) }\end{array}$ & $\begin{array}{l}\text { Frick et al. (European } \\
\text { Multi-Center) }\end{array}$ \\
\hline Inclusion period & $\begin{array}{l}\text { October 2008-October } \\
2013\end{array}$ & $\begin{array}{l}\text { May 2005-December } \\
2018\end{array}$ & August 1998-May 2020 \\
\hline $\begin{array}{l}\text { Pts transplanted/ } \\
\text { listed }(\mathrm{N})\end{array}$ & $9 / 14$ & $39 / 63$ & $13 /^{a}$ \\
\hline Cause of ARDS (N) & $\begin{array}{l}\text { Disinfectant inhalation (4) } \\
\text { Pneumonia (4) Near } \\
\text { drowning (1) }\end{array}$ & $\mathrm{n} / \mathrm{a}$ & $\begin{array}{l}\text { Viral (7) Bacterial (5) } \\
\text { Postoperative (1) }\end{array}$ \\
\hline $\begin{array}{l}\text { Median recipient } \\
\text { age }\end{array}$ & 39 & 35 & 29 \\
\hline $\begin{array}{l}\text { Median duration } \\
\text { of MV (days) }\end{array}$ & 11 & $\mathrm{n} / \mathrm{a}$ & 33 \\
\hline $\begin{array}{l}\text { Median hospital } \\
\text { stay (days) }\end{array}$ & 56 & 33 & 54 \\
\hline $\begin{array}{l}\text { In-hospital } \\
\text { mortality }\end{array}$ & $11.1 \%$ & $10.3 \%$ & $7.7 \%$ \\
\hline 1-y survival & $78 \%$ & $82.1 \%$ & $71.6 \%$ \\
\hline 3-y survival & $78 \%$ & $69.2 \%$ & $\mathrm{n} / \mathrm{a}$ \\
\hline 5-y survival & $\mathrm{n} / \mathrm{a}$ & $\mathrm{n} / \mathrm{a}$ & $54.2 \%$ \\
\hline
\end{tabular}

n/a; not available.

a Not reported.

${ }^{\mathrm{b}} \mathrm{MV}$; mechanical ventilation.

severe ARDS, the underlying cause of ARDS largely differed between the published cohorts. In the Korean study, half of the patients developed lung failure due to the inhalation of humidifier disinfectant $(n=7)$ while the second most frequent cause was pneumonia $(n=5)$. In the European series, viral $(n=7)$ and bacterial $(n=5)$ infections were the predominant causes of ARDS. ${ }^{43}$ The UNOS database study could not provide detailed data on ARDS cause.

There is general agreement that lung transplantation for ARDS is complex and the intra- and postoperative management is challenging. Thus, an outcome similar to other indications (ILD, CF, COPD) may not be expected. In fact, the data from the 3 above-mentioned cohort studies confirmed this assumption. All 3 series report prolonged mechanical ventilation after lung transplantation with a median length of mechanical ventilation (LMV) of 11 to 33 days $^{40,43}$ and a prolonged hospital stay with a median of 33 to 56 days (see Table 1). ${ }^{40,42,43}$ However, these results are comparable to other complex patient groups, especially those with acute on chronic lung disease who require ECLS bridging to lung transplant. ${ }^{44-48}$ Long-term survival following lung transplantation for ARDS was also lower compared with contemporary benchmarks. The Korean group reported 1- and 3-year survival rates of $78 \%$. One patient out of $9(11.1 \%)$ died in the immediate postoperative course. ${ }^{40}$ The UNOS series by Harano and colleagues reported survival rates of $82.1 \%$ at one, and $69.2 \%$ at 3 years, respectively. The authors also provided a propensity-score matched analysis comparing patients with ARDS with a control group of 79 patients with restrictive lung disease. A 2:1 matching included lung allocation score, sex, age, and transplant type ensuring a control group of equal complexity. The propensity-matched cohort showed similar longterm outcomes to the ARDS cohort with a 1-year survival of $85.9 \%$ and a 3 -year survival of $65.4 \%$. A further comparison of bridged versus nonbridged patients regardless of ARDS/non-ARDS diagnosis also showed no significant difference. ${ }^{42}$ In the European series reported by Frick and colleagues, one out of 13 patients died early postoperatively, resulting in an in-hospital mortality rate of $7.7 \%$. Survival rates were $71.6 \%$ at 1 year and $54.2 \%$ at 5 years. As these studies included patients going back as far as 1993, the possibility of an era effect on outcomes should be considered, especially as the European group reported improved outcomes for patients with ARDS transplanted after 2016. ${ }^{43}$ Nevertheless, patients bridged with ECMO to transplant reach comparable survival rates of $76 \%$ to $88 \%$ at 1 year, $61 \%$ to $83 \%$ at 3 years and $55 \%$ to 
$68 \%$ at 5 years. ${ }^{44-50}$ Indeed, our recent study from an international cohort of patients with COVID-19 ARDS supports that lung transplantation may be a viable life-saving treatment option for severe COVID-19-associated ARDS even those being supported on ECMO. Collectively, currently available evidence leads to the conclusion that carefully selected patients with ARDS can achieve lung transplantation outcomes comparable to other patients in similarly severe condition.

\section{Lung Transplantation Workup}

It is self-evident that in the acute setting of an ARDS, some routine examinations performed to determine lung transplant candidacy have to be waived. For instance, as most of the patients with ARDS who are considered for transplantation are young, the likelihood of an undetected malignancy or significant cardiovascular comorbidity is low. We suggest the following examinations are important:

- a computed tomography (CT) scan of the chest and abdomen

- virology (Ebstein-Barr virus, Cytomegalovirus, Hepatitis A/B, Human immunodeficiency virus)

- panel reactive antibody (PRA) test and unacceptable HLA antigens in case of presensitized patients

- an ultrasound examination of the peripheral vessels to evaluate for venous thrombosis

- in case of nonawake bridging a CT scan of the brain to exclude major bleeding/ischemia (though we acknowledge this may be a relative contraindication for some centers)

- echocardiography

- in patients aged greater than 50 years, CT coronary angiogram or left heart catheterization

- ultrasound of the liver/fibroscan

- no mammography, no coronary angiography, no colonoscopy, no gastroscopy

\section{Bridging a Patient with Acute Respiratory Distress Syndrome While Awake or Sedated}

Bridging patients awake has become an increasingly used practice in lung transplantation. In some centers, an awake patient is even considered a prerequisite for transplantation. In our opinion, there are mainly 2 reasons for this: (1) several studies have shown that the outcome of patients who can be bridged awake is significantly better compared with patients who are bridged sedated to. ${ }^{45,51,52}$ (2) The decision for lung transplantation is of such importance that a firstperson consent is considered necessary.
In our opinion, both arguments are only valid for patients suffering from chronic lung disease who require ECLS bridging-in ARDS they may not apply. Waking up patients with ARDS is often impossible, as unlike fibrosis patients who require ECLS bridging, patients with ARDS are usually severely sick. ${ }^{43}$ Their lung compliance is extremely poor with tidal volumes less than $100 \mathrm{~mL}$. These unique challenges often result in severe stress and episodes of desaturation.

Our perspective is that given the severity of the disease and the lack of alternative therapies in transplant candidates a personal consent can be waived in many European countries. This requires the consent of a health care proxy or adult representative. However, in cases whereby the implementation of such a representative (designated by a court) takes too long, the presumed will of the sedated patient has to be followed and a next-of-kin consent for transplantation is acceptable-under the assumption that the patient wants medically indicated treatment to save his/her life. When considering lung transplantation in patients with ARDS, the "right timing" is essential. Once the irreversibility of lung damage is confirmed, we recommend no attempts at weaning sedation to obtain personal consent. In critically ill patients, a longer ECLS time directly translates into higher complication rates, threating the success of a transplantation. ${ }^{53}$ This "window of opportunity" has to be considered when discussing the optimal time for listing patients with ARDS.

\section{Considerations for Delisting in Case of Deterioration}

As published evidence is limited to a few case reports and only 3 small case series, no clear recommendation can be given about when and under what conditions to delist a deteriorating patient. Ideally, ARDS transplant candidates should be in a stable condition with a single-system organ failure. However, dysfunction of other organs is frequently seen. A temporary kidney failure in a patient with a previous normal kidney function is generally not considered a contraindication for lung transplantation in our centers. Therefore, patients who require kidney replacement therapy during their wait time should not be delisted. However, cholestatic liver dysfunction can pose a significant challenge. Secondary sclerosing cholangitis (SCC) is a dreadful complication in patients requiring prolonged ECLS for ARDS. ${ }^{54,55}$ As therapeutic options in patients who develop SSC are limited and mortality is extremely high, we consider rising cholestasis parameters a contraindication to lung transplantation in patients with 
ARDS. The other 2 major contra-indications for ARDS lung transplantation are the development of uncontrolled diffuse bleeding during ECLS or a septic shock. However, if the reason for the septic shock is clearly the lung and the patient fails to stabilize, a bilateral pneumonectomy with a central Novalung/VA ECMO bridging concept can be considered. ${ }^{56}$

\section{SUMMARY}

Although the number of transplants for ARDS remains low compared with other indications, lung transplantation has become an established treatment of the subgroup of patients who do not recover. However, sufficient time on ECLS has to be given to determine the regenerative potential of the native lung. Patient selection is crucial and transplantation should be reserved for those without a prospect of recovery. This usually limits the option of lung transplantation to those who were relatively healthy before the onset of ARDS. Good long-term results have been described after lung transplant in the carefully selected cohort of patients with ARDS.

\section{CLINICS CARE POINTS}

- Mortality in patients with severe acute respiratory distress syndrome (ARDS) remains high

- A significant proportion of patients with severe ARDS develops irrecoverable lung damage and remains unweanable from mechanical life support

- Life transplantation may be a life-saving treatment in some of the patients that develop irrecoverable lung damage from severe ARDS

\section{DISCLOSURE}

$A B$ was supported by the National Institutes of Health (NIH HL145478, HL147290, and HL147575).

\section{REFERENCES}

1. Pham T, Rubenfeld GD. Fifty Years of Research in ARDS. The Epidemiology of Acute Respiratory Distress Syndrome. A 50th Birthday Review. Am J Respir Crit Care Med 2017;195(7):860-70.
2. Rubenfeld GD, Caldwell E, Peabody E, et al. Incidence and outcomes of acute lung injury. N Engl J Med 2005;353(16):1685-93.

3. Diamond M, Peniston Feliciano HL, Sanghavi D, et al. Acute Respiratory Distress Syndrome. StatPearls, Treasure Island: FL); 2021.

4. Frutos-Vivar F, Nin N, Esteban A. Epidemiology of acute lung injury and acute respiratory distress syndrome. Curr Opin Crit Care 2004;10(1):1-6.

5. Estenssoro E, Dubin A, Laffaire E, et al. Incidence, clinical course, and outcome in 217 patients with acute respiratory distress syndrome. Crit Care Med 2002;30(11):2450-6.

6. Esteban A, Anzueto A, Frutos F, et al. Mechanical Ventilation International Study, G., Characteristics and outcomes in adult patients receiving mechanical ventilation: a 28-day international study. JAMA 2002;287(3):345-55.

7. Zaccardelli DS, Pattishall EN. Clinical diagnostic criteria of the adult respiratory distress syndrome in the intensive care unit. Crit Care Med 1996; 24(2):247-51.

8. Bellani G, Laffey JG, Pham T, et al. Epidemiology, Patterns of Care, and Mortality for Patients With Acute Respiratory Distress Syndrome in Intensive Care Units in 50 Countries. JAMA 2016;315(8): 788-800.

9. Force ADT, Ranieri VM, Rubenfeld GD, et al. Acute respiratory distress syndrome: the Berlin Definition. JAMA 2012;307(23):2526-33.

10. Sedhai YR, Yuan M, Ketcham SW, et al. Validating Measures of Disease Severity in Acute Respiratory Distress Syndrome. Ann Am Thorac Soc 2021; 18(7):1211-8.

11. Zambon M, Vincent JL. Mortality rates for patients with acute lung injury/ARDS have decreased over time. Chest 2008;133(5):1120-7.

12. Burnham EL, Janssen WJ, Riches DW, et al. The fibroproliferative response in acute respiratory distress syndrome: mechanisms and clinical significance. Eur Respir J 2014;43(1):276-85.

13. Ketcham SW, Sedhai YR, Miller HC, et al. Causes and characteristics of death in patients with acute hypoxemic respiratory failure and acute respiratory distress syndrome: a retrospective cohort study. Crit Care 2020;24(1):391.

14. Bulpa PA, Dive AM, Mertens L, et al. Combined bronchoalveolar lavage and transbronchial lung biopsy: safety and yield in ventilated patients. Eur Respir J 2003;21(3):489-94.

15. Patel SR, Karmpaliotis D, Ayas NT, et al. The role of open-lung biopsy in ARDS. Chest 2004;125(1): 197-202.

16. Papazian L, Doddoli C, Chetaille B, et al. A contributive result of open-lung biopsy improves survival in acute respiratory distress syndrome patients. Crit Care Med 2007;35(3):755-62. 
17. Farjanel J, Hartmann DJ, Guidet B, et al. Four markers of collagen metabolism as possible indicators of disease in the adult respiratory distress syndrome. Am Rev Respir Dis 1993;147(5):1091-9.

18. Meduri GU, Tolley EA, Chinn A, et al. Procollagen types I and III aminoterminal propeptide levels during acute respiratory distress syndrome and in response to methylprednisolone treatment. Am J Respir Crit Care Med 1998;158(5 Pt 1):1432-41.

19. Clark JG, Milberg JA, Steinberg KP, et al. Type III procollagen peptide in the adult respiratory distress syndrome. Association of increased peptide levels in bronchoalveolar lavage fluid with increased risk for death. Ann Intern Med 1995;122(1):17-23.

20. Krein PM, Sabatini PJ, Tinmouth W, et al. Localization of insulin-like growth factor-I in lung tissues of patients with fibroproliferative acute respiratory distress syndrome. Am J Respir Crit Care Med 2003;167(1):83-90.

21. Marshall RP, Bellingan G, Webb S, et al. Fibroproliferation occurs early in the acute respiratory distress syndrome and impacts on outcome. Am J Respir Crit Care Med 2000;162(5):1783-8.

22. Bharat A, Machuca TN, Querrey M, et al. Early outcomes after lung transplantation for severe COVID19: a series of the first consecutive cases from four countries. Lancet Respir Med 2021;9(5):487-97.

23. Bharat A, Querrey M, Markov NS, et al. Lung transplantation for patients with severe COVID-19. Sci Transl Med 2020;12(574).

24. Reyfman PA, Walter JM, Joshi N, et al. Single-Cell Transcriptomic Analysis of Human Lung Provides Insights into the Pathobiology of Pulmonary Fibrosis. Am J Respir Crit Care Med 2019;199(12):1517-36.

25. Valenzi E, Bulik M, Tabib T, et al. Single-cell analysis reveals fibroblast heterogeneity and myofibroblasts in systemic sclerosis-associated interstitial lung disease. Ann Rheum Dis 2019;78(10):1379-87.

26. Habermann AC, Gutierrez AJ, Bui LT, et al. Singlecell RNA sequencing reveals profibrotic roles of distinct epithelial and mesenchymal lineages in pulmonary fibrosis. Sci Adv 2020;6(28):eaba1972.

27. Adams TS, Schupp JC, Poli S, et al. Single-cell RNAseq reveals ectopic and aberrant lung-resident cell populations in idiopathic pulmonary fibrosis. Sci Adv 2020;6(28):eaba1983.

28. Strunz M, Simon LM, Ansari M, et al. Alveolar regeneration through a Krt8+ transitional stem cell state that persists in human lung fibrosis. Nat Commun 2020;11(1):3559.

29. Kobayashi Y, Tata A, Konkimalla A, et al. Persistence of a regeneration-associated, transitional alveolar epithelial cell state in pulmonary fibrosis. Nat Cell Biol 2020;22(8):934-46.

30. Jiang P, Gil de Rubio R, Hrycaj SM, et al. Ineffectual Type 2-to-Type 1 Alveolar Epithelial Cell Differentiation in Idiopathic Pulmonary Fibrosis: Persistence of the KRT8(hi) Transitional State. Am J Respir Crit Care Med 2020;201(11):1443-7.

31. Wu H, Yu Y, Huang H, et al. Progressive Pulmonary Fibrosis Is Caused by Elevated Mechanical Tension on Alveolar Stem Cells. Cell 2020;180(1): 107-21.e17.

32. Lotfollahi M, Naghipourfar M, Luecken MD, et al. Query to reference single-cell integration with transfer learning. bioRxiv 2020;2020.

33. Joshi N, Watanabe S, Verma R, et al. A spatially restricted fibrotic niche in pulmonary fibrosis is sustained by M-CSF/M-CSFR signalling in monocytederived alveolar macrophages. Eur Respir J 2020; 55(1).

34. Zhou X, Franklin RA, Adler M, et al. Circuit Design Features of a Stable Two-Cell System. Cell 2018; 172(4):744-57.e17.

35. Steinberg KP, Hudson LD, Goodman RB, et al. Blood Institute Acute Respiratory Distress Syndrome Clinical Trials, N., Efficacy and safety of corticosteroids for persistent acute respiratory distress syndrome. N Engl J Med 2006;354(16):1671-84.

36. Beyer $\mathrm{C}$, Distler $\mathrm{JH}$. Tyrosine kinase signaling in fibrotic disorders: Translation of basic research to human disease. Biochim Biophys Acta 2013; 1832(7):897-904.

37. Yamaguchi Y, Takihara T, Chambers RA, et al. A peptide derived from endostatin ameliorates organ fibrosis. Sci Transl Med 2012;4(136):136ra71.

38. Wrighton $\mathrm{KH}$, Lin $\mathrm{X}$, Feng $\mathrm{XH}$. Phospho-control of TGF-beta superfamily signaling. Cell Res 2009; $19(1): 8-20$.

39. Machuca TN, Cypel M, Bharat A. Comment on Let's Build Bridges to Recovery in COVID-19 ARDS, not Burn Them! Ann Surg 2020;274(6):e870-1.

40. Chang Y, Lee SO, Shim TS, et al. Lung Transplantation as a Therapeutic Option in Acute Respiratory Distress Syndrome. Transplantation 2018;102(5): 829-37.

41. Botta M, Tsonas AM, Pillay J, et al. Ventilation management and clinical outcomes in invasively ventilated patients with COVID-19 (PRoVENT-COVID): a national, multicentre, observational cohort study. Lancet Respir Med 2020;9(2):139-48.

42. Harano T, Ryan JP, Chan EG, et al. Lung transplantation for the treatment of irreversible acute respiratory distress syndrome. Clin Transplant 2021;35(2): e14182.

43. Frick AE, Gan CT, Vos R, et al. Lung transplantation for acute respiratory distress syndrome: A multicenter experience. Am J Transplant 2021;22(1): 144-53.

44. Abdelnour-Berchtold E, Federici S, Wurlod DA, et al. Outcome after extracorporeal membrane oxygenation-bridged lung retransplants: a singlecentre experience. Interact Cardiovasc Thorac Surg 2019;28(6):922-8. 
45. Benazzo A, Schwarz S, Frommlet F, et al. Twentyyear experience with extracorporeal life support as bridge to lung transplantation. J Thorac Cardiovasc Surg 2019;157(6):2515-2525 e10.

46. Hoetzenecker K, Donahoe L, Yeung JC, et al. Extracorporeal life support as a bridge to lung transplantation-experience of a high-volume transplant center. J Thorac Cardiovasc Surg 2018; 155(3): 1316-1328 e1.

47. Ius F, Natanov R, Salman J, et al. Extracorporeal membrane oxygenation as a bridge to lung transplantation may not impact overall mortality risk after transplantation: results from a 7-year single-centre experience. Eur J Cardiothorac Surg 2018;54(2): 334-40.

48. Langer F, Aliyev P, Schafers HJ, et al. Improving Outcomes in Bridge-to-Transplant: Extended Extracorporeal Membrane Oxygenation Support to Obtain Optimal Donor Lungs for Marginal Recipients. ASAIO J 2019;65(5):516-21.

49. Hayanga JWA, Hayanga HK, Holmes SD, et al. Mechanical ventilation and extracorporeal membrane oxygenation as a bridge to lung transplantation: Closing the gap. J Heart Lung Transplant 2019; 38(10):1104-11.

50. Tipograf $Y$, Salna M, Minko E, et al. Outcomes of Extracorporeal Membrane Oxygenation as a Bridge to Lung Transplantation. Ann Thorac Surg 2019; 107(5):1456-63.

51. Biscotti M, Gannon WD, Agerstrand C, et al. Awake Extracorporeal Membrane Oxygenation as Bridge to Lung Transplantation: A 9-Year Experience. Ann Thorac Surg 2017;104(2):412-9.

52. Fuehner T, Kuehn C, Hadem J, et al. Extracorporeal membrane oxygenation in awake patients as bridge to lung transplantation. Am J Respir Crit Care Med 2012;185(7):763-8.

53. Oh DK, Hong SB, Shim TS, et al. Effects of the duration of bridge to lung transplantation with extracorporeal membrane oxygenation. PLoS One 2021; 16(7):e0253520.

54. Patel KV, Zaman S, Chang F, et al. Rare case of severe cholangiopathy following critical illness. BMJ Case Rep 2014;2014.

55. Tunney R, Scott J, Rudralingam V, et al. Secondary sclerosing cholangitis following extracorporeal membrane oxygenation for acute respiratory distress in polytrauma. Clin Case Rep 2018;6(9): 1849-53.

56. Cypel M, Waddell T, Singer LG, et al. Bilateral pneumonectomy to treat uncontrolled sepsis in a patient awaiting lung transplantation. J Thorac Cardiovasc Surg 2017; 153(4):e67-9. 